\title{
Bur open Suicidal feelings in the twilight of life: a cross-sectional population-based study of 97-year-olds
}

To cite: Fässberg MM, Östling S, BörjessonHanson A, et al. Suicidal feelings in the twilight of life: a cross-sectional populationbased study of 97 -year-olds. BMJ Open 2013;3:e002260. doi:10.1136/bmjopen-2012002260

- Prepublication history for this paper are available online. To view these files please visit the journal online (http://dx.doi.org/10.1136/ bmjopen-2012-002260).

Received 24 October 2012 Revised 2 January 2013 Accepted 8 January 2013

This final article is available for use under the terms of the Creative Commons Attribution Non-Commercial 2.0 Licence; see http://bmjopen.bmj.com

\section{Neuropsychiatric}

Epidemiology Unit, Section for Psychiatry and Neurochemistry, Institute of Neuroscience and Physiology, Sahlgrenska Academy, University of Gothenburg, Mölndal, Sweden

\section{Correspondence to} Madeleine Mellqvist Fässberg; madeleine.mellqvist@neuro. gu.se

\section{ABSTRACT}

Objective: To examine the occurrence of past month suicidal feelings in extreme old age. Further, to identify factors associated with such feelings.

Design: Cross-sectional population-based study.

Setting: Gothenburg, Sweden.

Participants: 269 adults (197 women, 72 men) without dementia born in 1901-1909 who participated in a psychiatric examination.

Main outcome measures: Death thoughts and suicidal feelings. The latter were rated in accordance with the Paykel questions (life not worth living, death wishes, thoughts of taking own life, seriously considered taking own life, attempted suicide) during the past month.

Results: One quarter of the sample (26.7\%) reported that they thought about their own death at least once a month. Past month thoughts that life was not worth living were acknowledged by $7.9 \%$ of the total sample, death wishes by $10.5 \%$ and thoughts of taking life by $3.8 \%$. Few had serious thoughts of taking own life $(0.8 \%)$ and none had attempted suicide. In all, $11.5 \%$ acknowledged some level of suicidal feelings. Most $(77.4 \%)$ of those who reported such feelings fulfilled criteria for neither major nor minor depression. Neither poor perceived health nor disability (hearing, vision and motor function) was associated with suicidal feelings. Problematic sleep and deficient social contacts were also related to suicidal feelings after adjustment for depression.

Conclusions: Suicidal feelings may occur outside the context of depression and disability in this age group. Results can inform clinicians who care for persons who reach extreme old age.

\section{INTRODUCTION}

Later life is a time of many losses for the individual, and this might help to explain the fact that high rates of suicide are observed in older adults. ${ }^{1}$ As populations age, clinicians can be expected to more frequently encounter persons with death wishes and thoughts of suicide. Prevalence rates of suicidal ideation in population-based studies

\section{ARTICLE SUMMARY}

Article focus

- Death wishes and suicidal ideation are common among older adults and have been shown to be associated with mental and physical illness, functional disability and social factors.

- The situation for persons who reach extreme old age is less clear.

Key messages

- While depression was associated with suicidal feelings, three-quarters of those who had such feelings fulfilled criteria for neither major nor minor depression. Screening programmes that aim at the identification and treatment of depression may fail to identify persons who have reached extreme old age and who could benefit from interventions.

- The results of this study suggest that attention to pain and sleep issues as well as increased opportunities for social contacts might constitute targets for the reduction of suicidal feelings in extreme old age.

Strengths and limitations of this study

- The strengths of this population-based study include the extreme high age of the participants and the fact that persons living in institutions were also included. Diagnostics were based on face-to-face interviews with clinicians trained in the use of a structured instrument for the rating of psychiatric symptoms.

- This is a cross-sectional study, and we can therefore not draw conclusions regarding causality. Associations may be bidirectional.

- Although this is the largest population-based study performed in extreme old age, some subgroups are small, which is reflected by the large Cls.

that focus specifically on older age groups range from $2 \%$ to $16 \% .^{2-6}$ The phenomenon is even more pronounced in the nursing home setting. ${ }^{7}$ Risk factors for suicidal ideation and behaviour in later life include mental and physical illness, functional 
disability and social factors. ${ }^{8} 9$ However, surprisingly little is known about these phenomena in extreme old age. Persons who reach their upper nineties represent a survival population, and findings regarding suicidal feelings in 'younger' older samples may prove to be of less relevance here. One might expect that thoughts about death are common at an age when natural death is imminent. But how common are suicidal feelings in those whose lives span over almost a century? Do such feelings arise in the context of depression and disability, as in younger age groups? How salient are social factors?

The first aim of this study was to estimate the frequency of death thoughts and suicidal feelings in a total population cohort of 97-year-olds without dementia. The second aim was to identify factors associated with suicidal feelings.

\section{METHODS}

Study participants

The study is part of the Gothenburg 95+ study which focuses on mental health in very late life. ${ }^{10}$ All persons living in Gothenburg, Sweden who reached the age of 97 years at some point during the period 1998-2007 ( $\mathrm{N}=973,817$ women and 156 men) were invited to participate. Names and addresses were obtained from the Swedish Population Register. Both persons living at home and in institutions were included. Forty-eight persons died before they could be contacted, eight persons were excluded due to insufficient knowledge of the Swedish language, four had emigrated and two could not be traced, leaving 911 persons eligible for inclusion ( 764 women and 147 men). A total of 591 (484 women, 107 men) agreed to participate (or, in cases with severe cognitive impairment, had proxy consent via next of kin). The overall response rate was $64.9 \%$. As previously reported, ${ }^{11}$ 2-year death rates were similar in participants $(52.8 \%)$ and non-participants $(50.9 \%)$. Persons who received a research diagnosis of dementia ( $n=322$, see the section Procedure) were excluded from the current study, leaving 269 individuals (197 women, 72 men).

\section{Procedure}

Participants were examined by a psychiatrist/psychiatric nurse/research psychologist during two home visits. A detailed description of procedures was recently reported. ${ }^{11}$ The structured examination included physical and neuropsychiatric examinations, a history of previous and current disorders, prescription drug use and assessments of activities of daily living and social factors. Participants were asked to identify a close relative who could give collateral information, and these were contacted for a telephone interview.

\section{Neuropsychological examination}

The neuropsychological examination included the Swedish version of the Mini Mental State Examination
(MMSE), ${ }^{12}$ as well as tests of short-term and long-term memory, abstract thinking, aphasia, apraxia and agnosia. Results from the examination and from the interview with next of kin were used to make dementia diagnoses in accordance with DSM III-R. ${ }^{13}$ For the purpose of this study, a research diagnosis of dementia was used as an exclusion criterion only.

\section{Psychiatric examination}

The semistructured examinations included ratings of psychiatric signs and symptoms during the preceding month in accordance with the Comprehensive Psychopathological Rating Scale (CPRS). ${ }^{14}$ Participants were asked how often they thought of their own death (never, occasionally, more frequently than once a month, more frequently than once a week, several times per week and daily). For the purpose of this paper, a person who acknowledged thoughts of own death more often than once a month was considered to have frequent thoughts of death. Thoughts about life-weariness, death wishes and suicide thoughts were rated according to Paykel et $a l^{15}$ using the following questions: (1) Have you ever felt that life was not worth living? (2) Have you ever wished you were dead, for instance, that you could go to sleep and not wake up? (3) Have you ever thought of taking your life, even if you would not really do it? (4) Have you ever reached the point where you seriously considered taking your life, or perhaps made plans how you would go about doing it? (5) Have you ever attempted to take your life? The most recent time any of these thoughts had occurred was noted. In this study, responses regarding the past month were used, in order to coincide with measures employed for psychiatric symptoms and signs. A person who responded with 'yes' to any of the five Paykel questions regarding the past month was considered to have suicidal feelings.

\section{Sleep}

Participants were asked if they were satisfied with their sleep (no/yes). A person who scored $\geq 4$ on the CPRS Reduced sleep item was considered to have reduced sleep. Correspondingly, a score $\geq 4$ on the increased sleep item was used to define increased sleep. Participants were asked if they had difficulties initiating sleep, which was defined as $>0.5 \mathrm{~h}$ latency, and if they experienced problems with early morning awakening. An estimation of total hours of sleep per $24 \mathrm{~h}$ period was made based on responses concerning times of sleep initiation and awakening for both night-time sleep and naps.

\section{Health}

Questions regarding the sudden onset of focal symptoms or acute aphasia, symptom duration and admission to hospital due to stroke/transient ischaemic attack (TIA) were asked both during the self-report examination and close-informant interview. The Swedish Hospital Discharge register also provided diagnoses of stroke and TIA. Only cases with evidence of focal symptoms (ie, 
paresis or aphasia), as documented by any of the above sources, were considered to have stroke/TIA. ${ }^{11}$

Hearing impairment was defined as deafness or a hearing defect which disturbed conversation during the interview despite hearing aid use. Vision impairment was defined as blindness or a defect which made some of the examination tasks impossible to perform despite own glasses or the use of a magnifying glass.

For the purpose of this study, a person was considered to have aches and pains when scoring $\geq 4$ on the CPRS pain item, corresponding to long-standing and disturbing aches or pains, need for pain relief or intensive disabling pains.

For participants born in 1905-1909 ( $\mathrm{n}=166)$, a question was added, How do you perceive your current health? Responses were dichotomised as follows: good (fairly good/good/very good) and poor (fairly poor/ poor/very poor).

\section{Motor functions}

Six different motor functions (dressing, eating, physical activity, spontaneous activity, personal hygiene and control of bladder and bowel) were examined in accordance with the Gottfries-Brane-Steen scale (GBS) ${ }^{16}$ This instrument has shown high reliability and validity. ${ }^{17}$ Each item is rated from 0 (normal function) to 6 (maximal disturbance), yielding a maximum score of 36 .

\section{Religiosity}

Participants were asked if they considered themselves to be religious (no/yes). Further, a person was considered 'actively religious' if they attended services or followed services by radio or TV.

\section{Social factors}

Detailed data on social factors were available for the subgroup born in 1905-1909 ( $\mathrm{n}=166)$. All of the following items were dichotomised (no/yes): Do you have a confidant? Do you have more than one confidant? Do you feel that you spend too little time with your children? Your grandchildren? With friends and acquaintances? With neighbours? Do you spend less time with friends and family than before retirement? Do you feel lonely? ${ }^{18}$

\section{Diagnostics}

Psychiatric diagnoses were made in accordance with the Diagnostic and Statistical Manual of Mental Disorders, Third Edition, Revised (DSM-III-R) ${ }^{19}$ as described previously. ${ }^{13}$ Minor depression was diagnosed in accordance with DSM-IV research criteria. ${ }^{20}$ Owing to a lack of information, we disregarded the 6-month duration criteria of psychotic symptoms for diagnosis of schizophrenia. We used a hierarchical diagnostic scheme. ${ }^{10}$ Depression (major depression and minor depression) or generalised anxiety disorder (GAD) was not diagnosed if a psychotic disorder was present. GAD was not diagnosed if major depression was present. Diagnostic entities were merged for analyses regarding psychiatric illnesses.
Schizophrenia and schizophreniform disorders were treated as one entity, psychotic disorder. This disorder also included delusional disorder and psychotic disorder not otherwise specified (NOS). Major depression and minor depression were merged into any depression. Anxiety disorder included GAD and phobic disorder (agoraphobia/social phobia/simple phobia).

\section{Statistical analysis}

The t-test was used to test differences in means. The $\chi^{2}$ and Fisher's exact tests were employed to analyse differences in proportions. Owing to the relatively small number of participants in some subgroups, exact logistic regression was used to analyse associations of interest. All independent variables that showed significant associations with suicidal feelings in the bivariate exact logistic regression analyses were analysed in separate multivariate exact logistic regression models, adjusting for sex and any depression. Three-year mortality was calculated from the date of examination, utilising dates of death obtained from the Swedish Population Register. Statistical analyses were performed with IBM SPSS Statistics, V.20 for Windows and SAS V.9.2. Results were considered significant when $\mathrm{p}<0.05$.

\section{RESULTS}

Demographic and diagnostic characteristics of the study sample are shown in table 1 . The proportion of those reporting thoughts about own death more than once a month was $26.7 \%$. One of 10 participants reported that they had experienced some level of suicidal feelings

Table 1 Demographic and diagnostic characteristics in a population sample of 97 -year-olds without dementia $(n=269)$

\begin{tabular}{lll}
\hline & N & Per cent \\
\hline Demographics & & \\
$\quad$ Female & $197 / 269$ & 73.2 \\
Education beyond mandatory & $109 / 189$ & 57.6 \\
$\quad$ Living in an institution & $77 / 266$ & 28.9 \\
Partner status (current) & & \\
Partner & $10 / 266$ & 3.8 \\
Divorced & $12 / 266$ & 4.5 \\
Widowed & $208 / 266$ & 78.2 \\
Always single & $36 / 266$ & 13.5 \\
Psychiatric disorders & & \\
Any depression & $22 / 269$ & 8.2 \\
Major depression & $8 / 269$ & 3.0 \\
Minor depression & $14 / 269$ & 5.2 \\
Anxiety disorder & $16 / 269$ & 5.9 \\
$\quad$ Generalised anxiety disorder & $8 / 269$ & 3.0 \\
Phobic disorder & $9 / 269$ & 3.3 \\
Psychotic disorder & $12 / 269$ & 4.5 \\
Schizophrenia & $6 / 269$ & 2.2 \\
Psychotic disorder NOS & $6 / 269$ & 2.2 \\
\hline NOS, not otherwise specified. & & \\
\end{tabular}


Table 2 One-month frequency of suicidal feelings* in a population sample of 97-year-olds without dementia, by sex $(n=269)$

\begin{tabular}{llllllll}
\hline & Women $(\mathbf{n}=\mathbf{1 9 7})$ & Per cent & Men $(\mathbf{n}=\mathbf{7 2})$ & Per cent & Total $(\mathbf{n}=\mathbf{2 6 9})$ & Per cent & $\mathbf{p}$ Valuet \\
\hline Any suicidal feelings & $27 / 197$ & 13.7 & $4 / 72$ & 5.6 & $31 / 269$ & 11.5 & 0.045 \\
Thought that life is not worth living & $17 / 196$ & 8.7 & $4 / 70$ & 5.7 & $21 / 266$ & 7.9 & 0.308 \\
Death wishes & $25 / 196$ & 12.8 & $3 / 70$ & 4.3 & $28 / 266$ & 10.5 & 0.033 \\
Thought of taking own life & $9 / 194$ & 4.6 & $1 / 70$ & 1.4 & $10 / 264$ & 3.8 & 0.206 \\
Seriously considered taking own life & $1 / 194$ & 0.5 & $1 / 70$ & 1.4 & $2 / 264$ & 0.8 & 0.461 \\
Attempted suicide & $0 / 194$ & $(-)$ & $0 / 70$ & $(-)$ & $0 / 264$ & $(-)$ & \\
\hline
\end{tabular}

${ }^{*}$ According to Paykel. ${ }^{15}$

†Sex differences, in accordance with Fisher's exact test.

during the last month, and this was more common in women (table 2). No sex difference could be shown regarding 1 month frequencies of thoughts that life was not worth living, but death wishes were more often endorsed by women. Thoughts of taking one's own life were reported by $3.8 \%$. Serious consideration of taking life was rare $(0.8 \%)$. None of the participants had attempted suicide during the past month.
Associations with suicidal feelings

Frequent thoughts of death were more common among individuals reporting suicidal feelings than those without such feelings $(70.0 \%$ vs $21.2 \%, \mathrm{p}=0.000)$. Over a quarter of those who never had a spouse/partner reported suicidal feelings, and there was a significant association with suicidal feelings (table 3). Individuals reporting suicidal feelings were less likely to have children than those

Table 3 Associations with past month suicidal feelings* $(n=269)$

\begin{tabular}{|c|c|c|c|c|c|}
\hline & $\begin{array}{l}\text { Suicidal feelings } \\
(n=31)\end{array}$ & Per cent & $\begin{array}{l}\text { No suicidal } \\
\text { feelings }(n=238)\end{array}$ & Per cent & p Value \\
\hline \multicolumn{6}{|l|}{ Demographics } \\
\hline Education beyond mandatory & $9 / 20$ & 45.0 & $100 / 169$ & 59.2 & 0.447 \\
\hline Living in an institution & $11 / 30$ & 36.7 & $66 / 236$ & 28.0 & 0.216 \\
\hline \multicolumn{6}{|l|}{ Partner status (current) } \\
\hline Partner & $0 / 31$ & $(-)$ & $10 / 235$ & 4.3 & \\
\hline Divorced & $2 / 31$ & 6.5 & $10 / 235$ & 4.5 & 0.418 \\
\hline Widow/widower & $21 / 29$ & 67.7 & $187 / 235$ & 79.6 & 0.105 \\
\hline Always been single & $8 / 31$ & 25.8 & $28 / 235$ & 11.9 & 0.039 \\
\hline Children & $10 / 31$ & 32.3 & $126 / 234$ & 53.8 & 0.019 \\
\hline Life events & $5 / 22$ & 22.7 & $26 / 167$ & 15.6 & 0.280 \\
\hline \multicolumn{6}{|l|}{ Death of a parent before age 16} \\
\hline Death among children/grandchildren & $8 / 18$ & 44.4 & $40 / 166$ & 24.1 & 0.061 \\
\hline \multicolumn{6}{|l|}{ Religion } \\
\hline Religious & $18 / 30$ & 60.0 & $133 / 236$ & 56.4 & 0.430 \\
\hline Active religiously & $12 / 30$ & 40.0 & $91 / 236$ & 38.6 & 0.514 \\
\hline \multicolumn{6}{|l|}{ Psychiatric disorders } \\
\hline Any depression & $7 / 31$ & 22.6 & $15 / 238$ & 6.3 & 0.007 \\
\hline Anxiety disorder & $4 / 31$ & 12.9 & $12 / 238$ & 5.0 & 0.097 \\
\hline Psychotic disorder & $1 / 31$ & 3.2 & $11 / 238$ & 4.6 & 0.587 \\
\hline \multicolumn{6}{|l|}{ Sleep } \\
\hline Dissatisfied with sleep & $26 / 30$ & 86.7 & $153 / 233$ & 65.7 & 0.013 \\
\hline Reduced sleep & $6 / 28$ & 21.4 & $34 / 233$ & 14.6 & 0.242 \\
\hline Difficulties in initiating sleep & $22 / 30$ & 73.3 & $103 / 235$ & 43.8 & 0.002 \\
\hline Early morning awakening & $5 / 30$ & 16.7 & $22 / 235$ & 9.4 & 0.174 \\
\hline Increased sleep & $1 / 28$ & 3.6 & $3 / 233$ & 1.3 & 0.367 \\
\hline \multicolumn{6}{|l|}{ Health } \\
\hline Stroke/TIA & $7 / 31$ & 22.6 & $37 / 238$ & 15.5 & 0.224 \\
\hline Aches and pains & $12 / 29$ & 41.4 & $58 / 237$ & 24.5 & 0.046 \\
\hline Poor perceived health & $3 / 13$ & 23.1 & $12 / 93$ & 12.9 & 0.270 \\
\hline \multicolumn{6}{|l|}{ Impairments } \\
\hline Hearing impairment & $10 / 30$ & 33.3 & $88 / 238$ & 37.0 & 0.431 \\
\hline Vision impairment & $8 / 31$ & 25.8 & $69 / 238$ & 29.0 & 0.447 \\
\hline
\end{tabular}

TIA, transient ischaemic attack.

*According to Paykel. ${ }^{15}$

†ln accordance with Fisher's exact test. 
without such feelings. Living in an institution was not associated with suicidal feelings.

Table 3 shows further that while depression was more than three times more common among participants with suicidal feelings than in those without, most of those who reported suicidal feelings fulfilled criteria for neither major nor minor depression. No association could be found with anxiety disorder or psychotic disorder. Few had a history of psychiatric inpatient or outpatient care, and proportions were similar in those with and without suicidal feelings $(3.2 \%$ vs $3.8 \%, p=0.677)$. Mean MMSE scores were almost identical in participants with and without suicidal feelings (25.23 vs25.72, $95 \%$ CI -0.99 to $1.96, \mathrm{p}=0.519$ ).

Table 3 shows further that nearly $90 \%$ of those reporting suicidal feelings were dissatisfied with sleep, compared to two-thirds of those without such feelings. Problematic sleep initiation was more common among those with suicidal feelings. However, the mean number of hours of sleep reported per day was similar among participants with and without suicidal feelings (7.7 vs $7.8,95 \%$ CI -0.71 to $0.87, \mathrm{p}=0.836$ ). Nearly $23 \%$ of those with suicidal feelings had a history of stroke/TIA, and the proportion was similar in those who did not report such feelings. Forty per cent of those with suicidal feelings reported aches and pains, a proportion significantly greater than that in the group without suicidal feelings. None of the participants in the total group rated their health as very poor and only $13 \%$ perceived their current health as rather poor/poor. No difference could be found between those with and without suicidal feelings.

Over one-third of the sample had a hearing impairment and more than one-quarter had vision impairment. However, no difference could be found between those with and without suicidal feelings in regard to these impairments. No difference in the mean motor GBS score could be shown between those with and without suicidal feelings $(5.0$ vs $3.8,95 \%$ CI -3.23 to
$0.80, \mathrm{p}=0.236)$. Over half of the participants died within 3 years; there was no significant difference in proportions between those with and without suicidal feelings $(64.5 \%$ vs $50.8 \%, \mathrm{p}=0.106)$.

\section{Results of regression analyses}

Table 4 shows results of regression analyses. Never having children was associated with suicidal feelings. However, this association did not remain in the adjusted analysis. Depression was associated with a fourfold increase in odds of having suicidal feelings, and the association remained after adjusting for sex. As suicidal ideation is a symptom of depression, we reanalysed data after removing this symptom from the diagnostic algorithm. This did not affect our results. Both dissatisfaction with sleep and difficulties initiating sleep were associated with a more than threefold increase in odds of having suicidal feelings. However, after adjusting for sex and depression, only difficulties initiating sleep remained an independent determinant.

\section{Suicidal feelings and social factors}

Detailed data regarding social interactions were available for participants born in 1905-1909 (table 5). Reports of too little time spent with friends and acquaintances and too little time spent with neighbours were associated with suicidal feelings (table 6). The same was the case for reports of perceived loneliness. Too little time spent with friends and acquaintances and too little time spent with neighbours remained significant in separate regression models adjusted for sex and depression. The strongest association was found between spending too little time with friends and acquaintances, which yielded a more than sixfold increase in odds in the adjusted model.

\section{DISCUSSION}

To our knowledge, this is the first population-based study to examine thoughts of death and suicidal feelings

Table 4 Results of separate exact logistic regression models showing odds of having past month suicidal feelings ${ }^{*}(n=269)$

\begin{tabular}{|c|c|c|c|c|c|c|}
\hline & Crude OR† & $95 \% \mathrm{Cl}$ & p Value & Adjusted OR‡ & $95 \% \mathrm{Cl}$ & p Value \\
\hline Sex & 2.69 & 0.89 to 11.0 & 0.089 & & & \\
\hline Always been single§ & 2.56 & 0.90 to 6.67 & 0.078 & & & \\
\hline Childrenף & 0.41 & 0.16 to 0.96 & 0.037 & 0.47 & 0.18 to 1.11 & 0.091 \\
\hline Any depression & 4.30 & 1.35 to 12.6 & 0.013 & $3.79^{\star *}$ & 1.18 to 11.2 & 0.025 \\
\hline Dissatisfied with sleep†† & 3.39 & 1.12 to 13.8 & 0.026 & 3.02 & 0.99 to 12.4 & 0.053 \\
\hline Difficulties in initiating sleepł & 3.51 & 1.43 to 9.50 & 0.004 & 3.52 & 1.41 to 9.73 & 0.004 \\
\hline Aches and pains ${ }^{\star \star \star}$ & 2.17 & 0.89 to 5.16 & 0.091 & & & \\
\hline 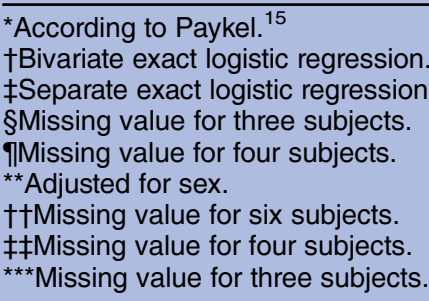 & $d$ for sex & y depression. & & & & \\
\hline
\end{tabular}


Table 5 Social characteristics in participants with and without past month suicidal feelings ${ }^{*}(n=166 \dagger)$

\begin{tabular}{|c|c|c|c|c|c|}
\hline & $\begin{array}{l}\text { Suicidal feelings } \\
(n=19)\end{array}$ & $\begin{array}{l}\text { Per } \\
\text { cent }\end{array}$ & $\begin{array}{l}\text { No suicidal feelings } \\
(n=147)\end{array}$ & $\begin{array}{l}\text { Per } \\
\text { cent }\end{array}$ & $\begin{array}{l}\mathbf{p} \\
\text { Value }\end{array}$ \\
\hline Has a confidant & $13 / 18$ & 72.2 & $105 / 141$ & 74.5 & 0.517 \\
\hline More than one confidant & $6 / 17$ & 35.3 & $59 / 135$ & 43.7 & 0.348 \\
\hline Too little time spent with children & $5 / 10$ & 50.0 & $18 / 104$ & 17.3 & 0.027 \\
\hline Too little time spent with grandchildren & $2 / 9$ & 22.2 & $21 / 101$ & 20.8 & 0.600 \\
\hline $\begin{array}{l}\text { Too little time spent with friends and } \\
\text { acquaintances }\end{array}$ & $8 / 16$ & 50.0 & $18 / 127$ & 14.2 & 0.002 \\
\hline Too little time spent with neighbours & $6 / 18$ & 33.3 & $11 / 138$ & 8.0 & 0.006 \\
\hline $\begin{array}{l}\text { Less time spent with friends and family than } \\
\text { before retirement }\end{array}$ & $8 / 16$ & 50.0 & $72 / 167$ & 25.2 & 0.041 \\
\hline Perceived loneliness & $12 / 18$ & 66.7 & $45 / 139$ & 32.4 & 0.006 \\
\hline
\end{tabular}

in extreme old age. While depression was associated with suicidal feelings, three-quarters of those who had such feelings fulfilled criteria for neither major nor minor depression. Social factors were strong determinants of suicidal feelings.

Difficulties in initiating sleep were associated with suicidal feelings even after depression was taken into consideration, which parallels the findings from a population study that included 'younger' older persons. ${ }^{21}$ However, it is important to stress that conclusions regarding causality cannot be drawn from cross-sectional studies. The association may be bidirectional. The wish to die may keep the individual awake, and problematic sleep may lead to a wish to die.

Somewhat unexpectedly, we could not show relationships with several health-related factors. Physical disability has been shown to associate with both suicidal feelings $^{21}$ and death by suicide ${ }^{22}$ in younger populations. Most participants in the current study reported good to very good health. This is a unique population sample consisting of cognitively relatively intact persons who have reached extreme old age. One might argue that results might be inflated by a tendency for persons in poor health to refuse participation to a greater extent than those in better health. However, our attrition analysis regarding mortality suggests that this is not the case. Another possibility is that individual perceptions of health and quality of life shift in the 'oldest old', 23 which could render health factors of less importance in explaining suicidal feelings in extreme high age.

A more than sixfold increase in the odds of suicidal feelings was observed in the context of unsatisfactory frequency of social contacts. The literature on social factors and suicidal behaviour in older people is extremely limited. ${ }^{24}$ The number and frequency of contacts have been reported in only a couple of studies. ${ }^{25} 26$ The approach used in the current study allowed participants to give a subjective view of their social relations. This is important as persons who are not socially isolated may also feel detached from the community. ${ }^{27}$

Table 6 Results of separate exact logistic regression models showing the association between social characteristics and past month suicidal feelings* $(n=166+)$

\begin{tabular}{|c|c|c|c|c|c|c|}
\hline & Crude OR & $95 \% \mathrm{Cl}$ & p Value & Adjusted OR§ & $95 \% \mathrm{Cl}$ & p Value \\
\hline Too little time spent with childrenף & 4.69 & 0.97 to 22.8 & 0.054 & & & \\
\hline Too little time spent with neighbours ${ }^{* *}$ & 5.67 & 1.46 to 20.7 & 0.011 & 5.00 & 1.10 to 20.9 & 0.036 \\
\hline $\begin{array}{l}\text { Too little time spent with friends and } \\
\text { acquaintances } \dagger \dagger\end{array}$ & 5.94 & 1.71 to 20.9 & 0.004 & 6.61 & 1.59 to 29.9 & 0.007 \\
\hline 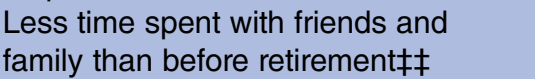 & 2.94 & 0.88 to 9.83 & 0.082 & & & \\
\hline Perceived loneliness ${ }^{\star \star \star}$ & 4.14 & 1.33 to 14.3 & 0.011 & 3.33 & 0.98 to 12.3 & 0.053 \\
\hline 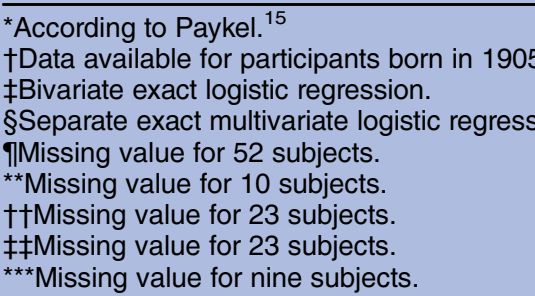 & $\begin{array}{l}09 \text { only. } \\
\text { adjusted fol }\end{array}$ & and any dep & ion. & & & \\
\hline
\end{tabular}




\section{Methodological considerations}

The strengths of the study include the extreme high age of the participants and the fact that persons living in institutions were also included in this population-based study. Diagnostics were based on face-to-face interviews with clinicians trained in the use of a structured instrument for the rating of psychiatric symptoms. The CPRS has been shown to have good reliability and validity in elderly clinical samples. ${ }^{28}$ Questions regarding death wishes and suicidal thoughts might be perceived as sensitive by some participants. Reporting suicidal feelings to an experienced psychiatrist, psychiatric nurse or psychologist might be easier than to a lay interviewer. It should be pointed out that the Paykel questions encompass a broad range of phenomena, and feelings of weariness of life and death wishes were far more common than serious suicidal ideation. Although this is the largest population-based study performed in extreme old age, the number of persons who seriously considered taking their lives during the past month was not large enough to allow for separate analyses. The problem of study power is further reflected by the large CIs observed for some of the analyses. Failure to show significance, for example, regarding the regression model involving aches and pains may be due to the study size. Finally, while the response rate $(65 \%)$ was fairly good considering the age group, it is possible that persons with suicidal feelings may have declined participation to a greater extent than those without such feelings. While this would result in an underestimation of past month suicidal feelings, it is unclear how this might have impacted on the associations studied.

\section{Implications}

Screening programmes that aim at the identification and treatment of depression may fail to identify persons who have reached extreme old age and who could benefit from interventions. The results of this study suggest that attention to pain and sleep issues as well as increased opportunities for social contacts might constitute targets for the reduction of suicidal feelings in very late life.

Acknowledgements The authors would like to thank all study participants and coworkers at the Neuropsychiatric Epidemiology Unit. A special thank you to Thomas Marlow and Erik Joas for consultation regarding statistics.

Contributors MMF analysed and interpreted the data and drafted the manuscript. SÖ, AB-H and IS interpreted the data and critically revised the manuscript. IS was responsible for planning the study and data collection. MW was responsible for supervision, and she also drafted and critically revised the manuscript and interpreted the data. She is the guarantor of the study.

Funding The study was made possible by grants from The Swedish Research Council 11267, 2005-8460, 825-2007-7462, 2008-7245-5895-70, 200962X-21079-01-3, The Swedish Council for Working Life and Social Research (no 2001-2835, no 2001-2849, 2005-0762, 2008-1210, Epilife 2006-1506), Stiftelsen Söderström-Königska Sjukhemmet, Stiftelsen Gamla Tjänarinnor, Bror Gadelius Foundation, Hjalmar Svenssons Foundation, Swedish Brain Power, The Alzheimer's Association (IIRG-03-6168, ZEN-01-3151) and the Bank of Sweden Tercentenary Foundation.
Competing interests None.

Ethics approval The Ethics Review Board at the University of Gothenburg approved the study. All participants were informed of their right to withdraw from the study at any time. Written consent was obtained. Among participants with clinical dementia, proxy informed consent was also obtained from the next of kin. All interviews were performed by highly experienced psychiatrists/ psychiatric nurses/research psychologists. When a respondent reported serious suicidal ideation or other serious psychopathology, the psychiatrist responsible for the medical study was informed and adequate care was initiated.

Provenance and peer review Not commissioned; externally peer reviewed.

Data sharing statement There are no additional data available.

\section{REFERENCES}

1. World Health Organization. Public health action for the prevention of suicide. http://apps.who.int/iris/bitstream/10665/75166/1/ 9789241503570_eng.pdf.

2. Jorm A, Henderson A, Scott $R$, et al. Factors associated with the wish to die in elderly people. Age Ageing 1995;24:389-92.

3. Skoog I, Aevarsson O, Beskow J, et al. Suicidal feelings in a population sample of nondemented 85-year-olds. Am J Psychiatry 1996;153:1015-20.

4. Rao R, Dening T, Brayne C, et al. Suicidal thinking in community residents over eighty. Int J Geriatr Psychiatry 1997;12:337-43.

5. Barnow $\mathrm{S}$, Linden $\mathrm{M}$, Freyberger $\mathrm{H}$. The relation between suicidal feelings and mental disorders in the elderly: results from the Berlin Aging Study (BASE). Psychol Med 2004;34:741-6.

6. Scocco P, Meneghel G, Caon F, et al. Death ideation and its correlates: survey of an over-65-year-old population. $J$ Nerv Ment Dis 2001;189:210-18

7. Scocco $P$, Fantoni G, Rapattoni $M$, et al. Death ideas, suicidal thoughts, and plans among nursing home residents. $J$ Geriatr Psychiatry Neurol 2009;22:141-8.

8. O'Connell H, Chin A, Cunningham C, et al. Recent developments: suicide in older people. BMJ 2004;329:895-9.

9. Van Orden K, Conwell Y. Suicides in late life. Curr Psychiatry Rep 2011:13:234-41.

10. Borjesson-Hanson A, Waern M, Ostling S, et al. One-month prevalence of mental disorders in a population sample of 95-year olds. Am J of Geriatr Psychiatry 2011;19:284-91.

11. Andersson $M$, Guo $X$, Borjesson-Hanson $A$, et al. A population-based study on dementia and stroke in 97 year olds. Age Ageing 2012;41:529-33.

12. Folstein M, Robins L, Helzer J. The mini-mental state examination. Arch Gen Psychiatry 1983;40:812.

13. Skoog I, Nilsson L, Landahl S, et al. Mental disorders and the use of psychotropic drugs in an 85-year-old urban population. Int Psychogeriatr 1993;5:33-48.

14. Asberg M, Montgomery S, Perris C, et al. A comprehensive psychopathological rating scale. Acta Psychiatr Scand Suppl 1978:5-27.

15. Paykel E, Myers J, Lindenthal J, et al. Suicidal feelings in the general population: a prevalence study. Br J Psychiatry 1974;124:460-9.

16. Gottfries $\mathrm{C}$, Brane $\mathrm{G}$, Gullberg B, et al. A new rating scale for dementia syndromes. Arch Gerontol Geriatr 1982;1:311-30.

17. Brane G, Gottfries C, Winblad B. The Gottfries-Brane-Steen scale: validity, reliability and application in anti-dementia drug trials. Dement Geriatr Cogn Disord 2001;12:1-14.

18. Mellqvist M, Wiktorsson S, Joas $\mathrm{E}$, et al. Sense of coherence in elderly suicide attempters: the impact of social and health-related factors. Int Psychogeriatr 2011;23:986-93.

19. American Psychiatric Association. Diagnostic and Statistical Manual of Mental Disorders, 3rd edn. revised. Washington DC, American Psychiatric Association, 1987.

20. American Psychiatric Association. Diagnostic and Statistical Manual of Mental Disorders, Fourth edn. Washington DC, American Psychiatric Association, 1994.

21. Lapierre S, Boyer R, Desjardins S, et al. Daily hassles, physical illness, and sleep problems in older adults with wishes to die. Int Psychogeriatr 2012;24:243-52.

22. Kaplan M, McFarland B, Huguet N, et al. Physical illness, functional limitations, and suicide risk: a population-based study. $A m$ J Orthopsychiatry 2007;77:56-60.

23. Wilhelmson K, Andersson C, Waern M, et al. Elderly people's perspectives on quality of life. Ageing Soc 2005;25:585-600. 
24. Fassberg $\mathrm{M}$, Van Orden $\mathrm{K}$, Duberstein $\mathrm{P}$, et al. A systematic review of social factors and suicidal behavior in older adulthood. Int $J$ Environ Res Public Health 2012;9:722-45.

25. Bartels S, Coakley E, Oxman T, et al. Suicidal and death ideation in older primary care patients with depression, anxiety, and at-risk alcohol use. Am J Geriatr Psychiatry 2002;10:417-27.

26. Turvey $\mathrm{C}$, Conwell $\mathrm{Y}$, Jones $\mathrm{M}$, et al. Risk factors for late-life suicide: a prospective, community-based study. Am J Geriatr Psychiatry 2002;10:398-406.
27. Crocker L, Clare L, Evans K. Giving up or finding a solution? The experience of attempted suicide in later life. Aging Ment Health 2006;10:638-47.

28. Van der Laan N, Schimmel A, Heeren T. The applicability and the inter-rater reliability of the Comprehensive Psychopathological Rating Scale in an elderly clinical population. Int $J$ Geriatr Psychiatry 2005;20:35-40. 